Supplement of The Cryosphere, 10, 2693-2719, 2016

http://www.the-cryosphere.net/10/2693/2016/

doi:10.5194/tc-10-2693-2016-supplement

(C) Author(s) 2016. CC Attribution 3.0 License.

(c) (1)

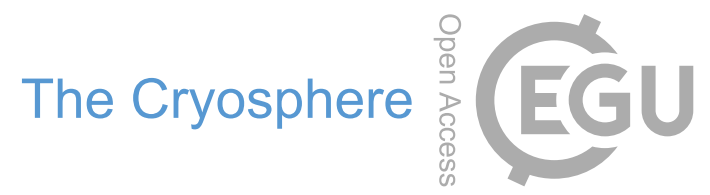

Supplement of

\title{
Semi-automated calibration method for modelling of mountain permafrost evolution in Switzerland
}

\section{A. Marmy et al.}

Correspondence to: Antoine Marmy (antoine.marmy@gmail.com)

The copyright of individual parts of the supplement might differ from the CC-BY 3.0 licence. 


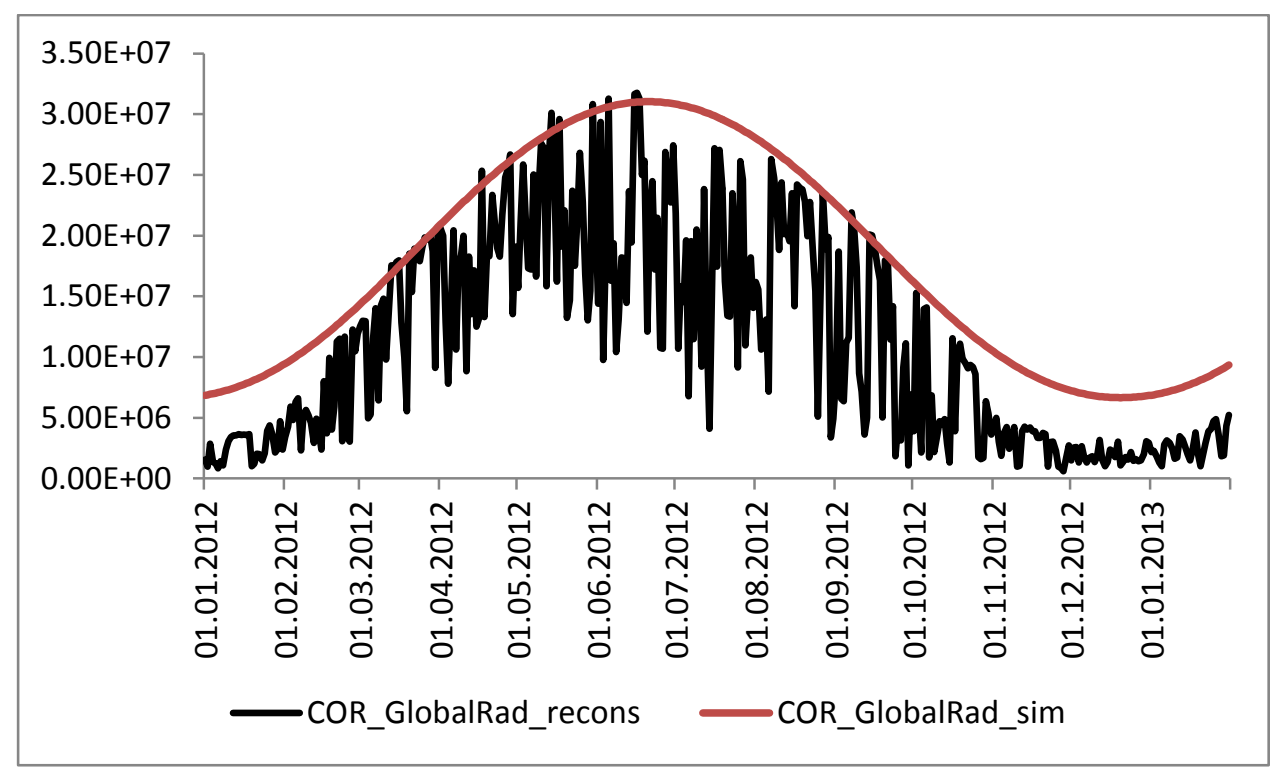

Supplementary Figure 1: Comparison of reconstructed (black) and model-estimated (red) global radiation at COR for the year 2012. 